\title{
DÜBLIN
}

Technological University Dublin

ARROW@TU Dublin

\section{Risk Registers: Structuring data collection to develop risk intelligence}

\author{
Maria Chiara Leva \\ Technological University Dublin, maria.leva@tudublin.ie \\ Nora Balfe \\ Trinity College Dublin \\ B. McAleer \\ ESB Generation
}

See next page for additional authors

Follow this and additional works at: https://arrow.tudublin.ie/schfsehart

Part of the Engineering Commons

\section{Recommended Citation}

Leva, M.C., Balfe, N. \& McAleer, B. (2017). Risk Registers: Structuring data collection to develop risk intelligence. Safety Science, vol. 100, part B, December 2017, pp. 143-156. doi.org/10.1016/ j.ssci.2017.05.009

This Article is brought to you for free and open access by the School of Food Science and Environmental Health at ARROW@TU Dublin. It has been accepted for inclusion in Articles by an authorized administrator of ARROW@TU Dublin. For more information, please contact arrow.admin@tudublin.ie, aisling.coyne@tudublin.ie, gerard.connolly@tudublin.ie.

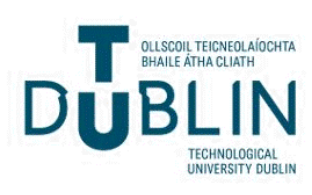


Authors

Maria Chiara Leva, Nora Balfe, B. McAleer, and M. Rock

This article is available at ARROW@TU Dublin: https://arrow.tudublin.ie/schfsehart/270 
Journals Books Register

Sign in

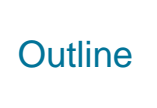

Download

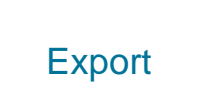

Search ScienceDirect

Advanced

\section{Safety Science}

Available online 9 June 2017

In Press, Corrected Proof

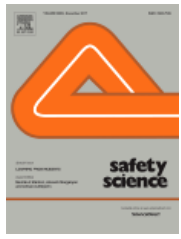

Recommended articles

Redefining the incidents to learn fr... Safety Science, Volume 99, Part A, 2...

Download PDF

View details

Occupational factors related to slip... Safety Science, 2017

Download PDF

View details

A two-wave study on workplace bu... Safety Science, Volume 100, Part A, ...

Download PDF

View details

View more articles

Citing articles (0)
Highlights

- Development of an integrated company-wide risk register.

- $\quad$ End user engagement and feedback on the requirements for the tool.

- Definition of a suitable method for risk aggregation.

- $\quad$ Link with relevant performance data for dyni input in the risk register.

- $\quad$ Controls of mitigating strategies in the risk register.

\section{Personalized recommendations}

Receive weekly emails based on what you have recently read across our journals and books.

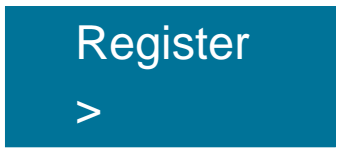

Sign in

$>$

\section{Abstract}

This paper presents the results of the development and 
implementation of a company-wide risk register, based on a clear set of data structures. A case study from an electricity generation company is presented and the process followed is described. The results of the case study indicated areas where the concept of risk registers could be extended to make better use of existing data and to support continuous improvement of risk management. Six key areas are discussed (1) aggregation of risks across the business, (2) supporting controls over mitigation measures, (3) improved estimation of event likelihood, (4) integrating with critical asset registers, (5) improving risk communication, and (6) linking with day-to-day operational practice. The paper concludes with a framework for placing risk registers at the heart of Process Safety.

\section{Keywords}

Risk register; Risk management; Risk assessment; Process safety

\section{Introduction}

In order to maintain safe operations, organisations must continuously review and monitor their risks. This means that the results of safety studies and/or the evidence of issues collected from operational experience must be translated into a format that can be analysed, reviewed and acted upon, and new data about the level of risk continuously collected to keep the safety information up to date (Monferini et al., 2013). This helps to create an 'informed culture', defined by Reason (1997) as a culture in which both management and operators are informed of and knowledgeable about the factors that influence safety as a whole. When the available information is shared between all applicable levels of the organisation, a Common Operational Picture (COP) can be created as the basis for safe and reliable system operation (Kontogiannis et al., this issue). One method of creating this shared understanding, or COP, is through the development and implementation of a risk register.

A risk database, or risk register, is a central tool for organisations to use to monitor and reduce risks, both those identified during 
initial safety assessments and those emerging during operations (Whipple and Pitblado, 2010). The risk register should contain all analysed risks and should prioritise the areas that require managerial attention and typically contains information describing each risk, an assessment of the likelihood and consequences, a ranking according to a risk matrix, the risk owner, and information on the mitigations to be put in place (Filippin and Dreher, 2004). When populated with information on each risk, including risk ranking, the risk register can analysed to present the risk profile for different aspects of the organisation (Filippin and Dreher, 2004). When reviewed and updated over time, it can also be analysed to present trends within the risk profile and focus management attention on the highest risk activities or facilities (Whipple and Pitblado, 2010).

Risk registers are used in a variety of industries, e.g. medicine (Brown, 2004) and construction (Dunović et al., 2013), as well as high hazard industries such as oil and gas (Hasle et al., 2009) and electricity generation (Leonard, 1995). They are typically used either to support safe operations or to support safe and efficient project management (e.g. De Zoysa and Russell, 2003). Cooke-Davies (2002) found that the adequacy with which a visible risk register was maintained was one of the key success factors for project management. Patterson and Neailey (2002) highlight the importance of the risk register and suggest that the benefit of a risk register is as a method to enable all stakeholders to "consciously evaluate and manage the risks as part of a decision making process" (pp. 365). They also note the importance of the risk register in documenting the process of reducing risk and introducing mitigations. However, Kutsch and Hall (2010) warn of the danger of risk registers becoming 'tick-box' exercises when the owners and contributors do not have a real ability to influence the risks - the danger of irrelevance. Despite the clear importance of risk registers in the risk management process, there is very little guidance on their development and implementation (Dunović et al., 2013).

Research conducted by the Design Information Group at Bristol University found that $67 \%$ of their questionnaire respondents working in Engineering Design project, documented their risks on either a paper or computer-based risk register (Crossland et al., 1998). However these were generally individual solutions, 
usually specific to the organisation and sometimes even specific to a location and hosted locally suggesting the format of a individual risk register than a company wide shared solution (Patterson and Neailey, 2002).

This paper attempts to address the gap in guidance on construction of risk registers by describing the results of a case study in which a risk register was established in an electricity generation company across multiple locations and the preliminary results were used for Management Review decisions. The single central risk register is aimed at collating risks from across the business, including various power stations across different geographical locations. The objectives of the project were:

- $\quad$ To develop a risk register data structure supporting consistent hazard identification and risk rating across different sites;

- $\quad$ To develop equivalent severity and frequency scales for different loss types and for application across different business units, such as operations, maintenance, finance, HR, etc.;

- $\quad$ To use the risk register to highlight key business risks to senior management;

- $\quad$ To use the risk register to gather information about mitigation measures in place and their effectiveness;

- $\quad$ To embed the risk register within a risk management process and share good practices across the company.

\subsection{Description of the case study}

The analysis presented in this paper is based on the development and implementation of a company wide risk register in an electricity-generating organisation in the Republic of Ireland. As part of an on-going process of Process Safety improvement, the organisation identified a need to advance the identification, analysis and management of risks across the business, and to hold these risks in a format that facilitated comparison and tracking. A project team was therefore assembled, with representatives from different stations and specialisms, to create a risk register capable of meeting the 
business' needs. The researchers were embedded in this team, and helped to facilitate the process. This paper discusses the process followed in the development and implementation of the risk register solution, evaluates the strengths and weaknesses of the solution, and finally applies the lessons learned to propose a framework for safety and risk management with a risk register as the central point.

\section{Developing a risk register}

\subsection{Key components}

Risk registers may take a variety of formats, but some there are some key components that are necessary to enable the management of risk in this format. First is the description of the risk, and a unique identification number to facilitate tracking. A concise description is necessary to allow users and reviewers to understand what is being documented. A more comprehensive description may also be provided, particularly for complex risks or those that have a long history. Each risk must have an indication of its priority, in the form of a risk ranking. Risk rankings are typically calculated from the product of the severity and likelihood of the risk. The calculation may be more or less sophisticated, depending on the data available. Finally, the actions required to improve or manage a risk should be documented, along with the overall risk owner who is responsible for ensuring progress of the risk against the planned timescales (dates). The risk owner may not be responsible for the individual actions required, as these may be spread across a diverse workforce, but they are responsible for ensuring overall progress. Complex or detailed actions may be held in a separate document, but a summary should always be available in the risk register. Table 1 summarises the core components of a risk register.

Table 1. Risk register core components.

\section{Element Description}

Risk ID A unique identification number for each risk

Risk A concise description or title for the risk 
Risk registers: Structuring data collection to develop risk intelligence - ScienceDirect

\section{Description}

Risk A quantification of the risk, based on severity and likelihood

ranking

Owner The person responsible for managing the risk and ensuring actions against it are completed

Actions A list of actions for each risk

Dates The date of entry and modification should be held for each risk to assist with reviews. Action target and completion dates should also be included

Additional components may be incorporated into a risk register, including documentation of existing controls in order to assist with monitoring their continued application and effectiveness, the risk status (e.g. open, closed, increasing, decreasing, etc.) to assist with tracking the overall risk profile, the type of risk and associated losses (e.g. safety, financial, reputational, legal, etc.), and the target risk level.

To facilitate risk evaluation, a risk register should be supported with a risk matrix and associated severity and likelihood scales. Different processes and parts of the organisation may already be using matrices and scales, and in order to apply a companywide risk register, these may need to be aligned for consistency.

\subsection{Problem definition}

Risk management during operations relies on the on-going identification, evaluation, and monitoring of risks with the potential to affect safety or performance. The partner organisation in this case study, had an existing process which relied on the plant managers from each station across the business reporting their 'Top 10' risks to a central risk manager who collated and analysed the full set for presentation to senior management. A number of issues were identified with this process, particularly:

- It was labour intensive;

- $\quad$ Not transparent to the stations reporting risks;

- $\quad$ Did not facilitate learning across the organisation; 
- $\quad$ Not consistent in the reporting and rating of risks;

- $\quad$ Not comprehensive in the types of risks covered;

- $\quad$ Only updated quarterly;

- $\quad$ No ability to data-mine or trend the data.

In order to better manage process safety, the company required a single risk register to be developed that supported the identification and management of operational risks encompassing all business units into a single dynamic source. The risk register should also include a process for communication and review of the top business risks and control measures by senior management at a defined frequency. Finally, feedback and value to the end users (stations) inputting their risks should also be taken into account. Possible value for end users includes:

- $\quad$ possibility to share best practices or solutions with other stations/users having similar problems

- $\quad$ gather feedback form management about their risk and possible mitigation strategy coordinated centrally rather than locally

- $\quad$ use the risk register to support performance reporting against company objectives.

\subsection{Gathering requirements for solution development}

The case study was developed within a FP7 EU funded project on Total Safety Management called TOSCA (Leva et al., 2014). During the scope of the project, a series of workshops were coordinated by the academic partner in collaboration with the energy company to involve all the key stakeholders and define a vision and action plan for the risk register. Participants in the workshops represented individual generation stations from a safety, technical and financial point of view as well as corporate specialists in risk management, environmental safety and occupational and process safety. The inclusion of this wideranging expertise is suggested as the first recommendation from this work. However, several challenges arose during these workshops (see Balfe et al., 2014 for more detail), with the first being the need to develop a shared understanding of risk and 
hazard concepts. It cannot be taken for granted that a potentially diverse user group will all have a similar understanding of the terms 'hazard' and 'risk' and a brief training session was used to reinforce shared understanding of the terms. A further challenge that emerged during the early development was the differences between individual and corporate perspectives on risk. Risks may have different consequences depending on the viewpoint of an individual/group (Leva et al., 2012). For example, in the energy industry, a transformer failure would have high consequences for an individual generation station as they cannot export the electricity generated. However, it is not necessarily an issue for the business as they may be able to compensate with another station, and can even be a benefit to those other stations that will receive a higher payment for exporting more electricity. These different perspectives must be reconciled by monetizing values of those risks and aggregating them at overall business level.

Ultimately, the workshops led to the identification of 10 high level requirements (Table 2) and the supporting components of a risk matrix and associated loss and consequence tables. These high level requirements were generated specifically for the case study, but are generally applicable to company wide risk registers. Their purpose is to guide the development of both the specific solution for the risk register, and the supporting risk management process. A strong risk management process is required to ensure that the effort invested in development, implementing, populating and maintaining the Risk Register is translated into real safety improvements. To support this, a business process map and use case was generated to describe the roles and activities involved in the risk management process. This was refined during the workshops to generate a practical, stable solution that could be applied across the business. Fig. 1 reports the use case diagrams developed for the company involved.

Table 2. High-level requirements for risk register.

\section{ID Description (high level requirement)}

HLR1 Create a comprehensive and consistent risk management process 
HLR2 Reports/matrices shall provide an update of the risk levels within the business at a particular moment of time and take into account possible short term emerging risks i.e. weather extremes, equipment type faults, internal or external incident investigations, etc.

HLR3 The risk management system shall ensure that all potential hazards are identified and assessed

HLR4 The risk management system shall ensure that adequate control measures are put in place

HLR5 The risk management system shall ensure that control measures remain effective in the management of each risk

HLR6 All risk information shall be held in a single risk register which encompasses all business risks into a single dynamic source

HLR7 Periodic hazards and risk reviews shall be carried out

HLR8 All hazards shall be identified, and periodic hazards and risk reviews shall be carried out

HLR9 Key performance indicators shall be developed to ensure that the key hazards have been identified and assessed, that all business risks are regularly reviewed, and that control measures are in place and effective in reducing risks to a tolerable level

HLR10 The system shall be fully aligned to the company's strategy, with strong and positive management leadership thus ensuring that the business risks are understood from the board room to the control room, with real time risk management decision making and a comprehensive risk assessment process which systematically identifies, assesses and appropriately manages risk from the organisation operations

HLR11 A single company procedure for measurement and reporting of risk shall be delivered and tolerable risk shall be clearly defined, understood and utilised, thus meeting a fundamental requirement of Process Safety 


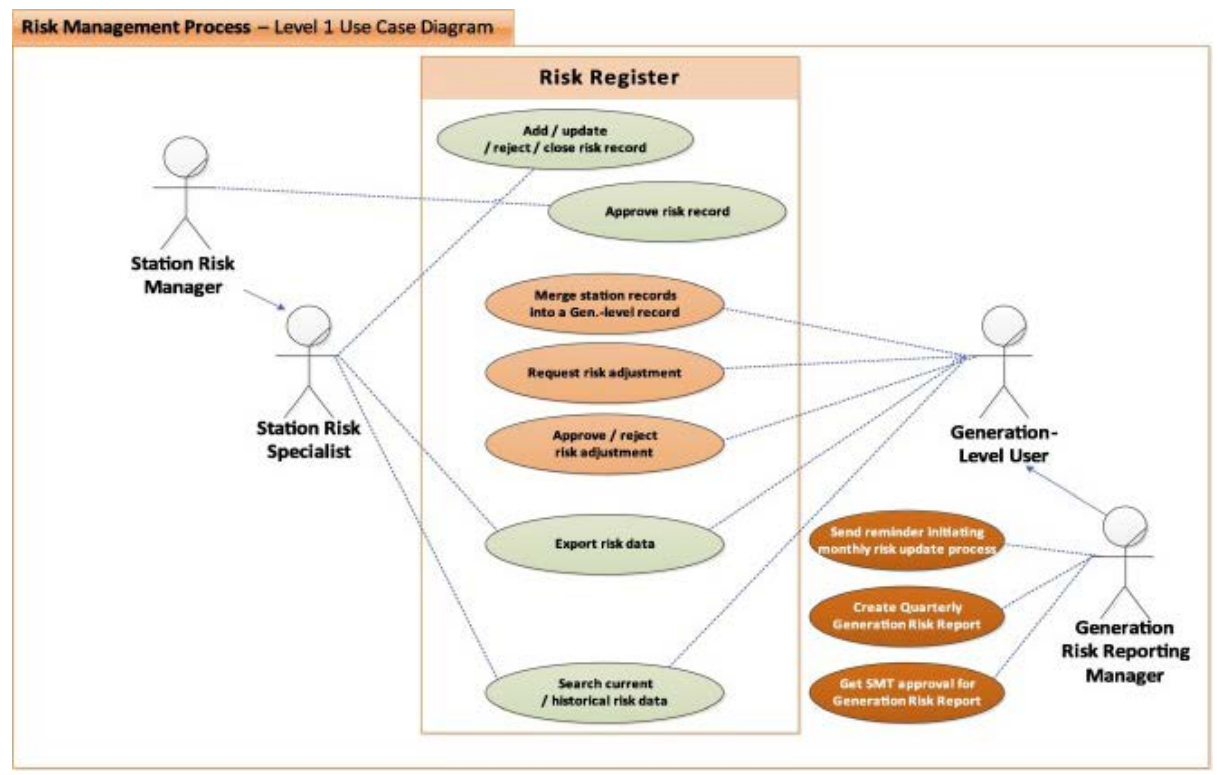

Download high-res image (409KB) Download full-size image

Fig. 1. Use case for Risk Register in the company.

\subsection{Risk register supporting elements}

Four main supporting elements were developed for the risk register:

1. The consequence/loss categories;

2. The likelihood categories;

3. The risk matrix;

4. The hazard categories.

Initial versions for each of these were included in the first rollout of the Risk Register, and were subsequently iterated on the basis of user feedback during the first year of use. The elements shown below are current at the time of writing, but as the Risk Register further embeds and business requirements change, these elements may also continue to evolve.

\subsubsection{Consequence/loss categories}

One of the central functions of the risk register is to help judge where money should be invested. If this decision were to be based only on generated income, then the larger plants would receive a huge share of the available funds. However, it may also be important for safety and environmental reasons that the 
smaller plants are properly maintained. Therefore, the categories of losses covered by the risk register in terms of equivalent monetised values are not only the ones explicitly linked to financial implications but also the ones covering technical performance, safety, environmental and reputational effects. In order to maintain consistency the equivalent scales developed for each loss type are broadly equivalent. The scales developed for each category are shown in Table 3. It is always possible for a user to indicate if a certain type of loss category does not apply.

Table 3. Loss categories used.

\begin{tabular}{|c|c|c|c|c|c|}
\hline & Safety & Environment & Financial & $\begin{array}{l}\text { Technical } \\
\text { performance }\end{array}$ & Reputational \\
\hline 1 & Minor injury & Minor impact & $<€ 100 \mathrm{~K}$ & $\begin{array}{l}€ 10 \text { k repair } \\
<1 \text { day } \\
\text { outage }\end{array}$ & $\begin{array}{l}\text { Informal/local } \\
\text { complaint }\end{array}$ \\
\hline 2 & $\begin{array}{l}\text { 1-2 day lost } \\
\text { time injury }\end{array}$ & $\begin{array}{l}\text { Moderate } \\
\text { (short) impact }\end{array}$ & $<€ 1 \mathrm{~m}$ & $\begin{array}{l}€ 75 \text { k repair } \\
<1 \text { week } \\
\text { outage }\end{array}$ & $\begin{array}{l}\text { Formal } \\
\text { complaint to } \\
\text { company }\end{array}$ \\
\hline 3 & $\begin{array}{l}\text { Serious } \\
\text { injury }\end{array}$ & $\begin{array}{l}\text { Significant } \\
\text { impact; minor } \\
\text { license } \\
\text { breach }\end{array}$ & $<€ 10 \mathrm{~m}$ & $\begin{array}{l}€ 100 \text { k repair } \\
>1 \text { day } \\
\text { shutdown }\end{array}$ & $\begin{array}{l}\text { Local media } \\
\text { coverage/formal } \\
\text { complaint from } \\
\text { regulator }\end{array}$ \\
\hline 4 & $\begin{array}{l}1 \text { fatality, or } \\
\text { multiple } \\
\text { health } \\
\text { effects or } \\
\text { permanent } \\
\text { incapacity }\end{array}$ & $\begin{array}{l}\text { Significant, } \\
\text { long-term } \\
\text { impact; } \\
\text { temporary } \\
\text { shutdown }\end{array}$ & $<€ 50 \mathrm{~m}$ & $\begin{array}{l}€ 1 \text { m repair } \\
>1 \text { week } \\
\text { shutdown }\end{array}$ & $\begin{array}{l}\text { National } \\
\text { coverage/formal } \\
\text { inspection }\end{array}$ \\
\hline 5 & $\begin{array}{l}\text { Multiple } \\
\text { fatalities }\end{array}$ & $\begin{array}{l}\text { Major, } \\
\text { permanent } \\
\text { damage, long } \\
\text { term } \\
\text { shutdown }\end{array}$ & $>€ 50 \mathrm{~m}$ & $\begin{array}{l}€ 50 \text { m repair } \\
>1 \text { week } \\
\text { shutdown }\end{array}$ & $\begin{array}{l}\text { International } \\
\text { coverage }\end{array}$ \\
\hline
\end{tabular}




\subsubsection{Likelihood categories}

The likelihood scale (Table 4) includes probability ranges to estimate corresponding classes of monetized risk values to be able to aggregate risks that are in common across multiple stations with different likelihood and exposure in the various impact categories. Both the likelihood scale and the loss categories are based on the MIL-ST-882. This Military Standard has been recognised as a guiding light in system safety within not only the defence sector but also in transport, energy and aviation.

Table 4. Revised likelihood scale for the risk matrix.

\begin{tabular}{|c|c|c|c|c|}
\hline Rating & Name & Description & $\begin{array}{l}\text { Likelihood } \\
\text { per year }\end{array}$ & $\begin{array}{l}\text { Mean value } \\
\text { of range } \\
\text { considered }\end{array}$ \\
\hline 1 & Unlikely & $\begin{array}{l}\text { So unlikely, it can be assumed } \\
\text { occurrence may not be } \\
\text { experienced }\end{array}$ & $<0.01 \%$ & $\begin{array}{l}\text { Mean value } \\
0.005 \%\end{array}$ \\
\hline 2 & Remote & $\begin{array}{l}\text { Very unlikely but possible to } \\
\text { occur }\end{array}$ & $0.1-0.01 \%$ & $\begin{array}{l}\text { Mean value: } \\
0.05 \%\end{array}$ \\
\hline 3 & Possible & $\begin{array}{l}\text { Possible to occur sometimes } \\
\text { in the work life }\end{array}$ & $1-0.1 \%$ & $\begin{array}{l}\text { Mean value: } \\
0.5 \%\end{array}$ \\
\hline 4 & Probable & $\begin{array}{l}\text { Will occur several times in the } \\
\text { work life }\end{array}$ & $10-1 \%$ & $\begin{array}{l}\text { Mean value: } \\
5.5 \%\end{array}$ \\
\hline 5 & Frequent & Likely to occur & 100-10\% & $\begin{array}{l}\text { Mean value: } \\
55 \%\end{array}$ \\
\hline
\end{tabular}

\subsubsection{Risk matrix}

As discussed in the literature risk matrices are very popular but should be used with caution, and with careful explanations of embedded judgments (Cox, 2008). The likelihood and severity categorisations (and therefore the risk ratings) require subjective interpretation, and different users may obtain different ratings of the same quantitative risks; According to Cox (2008) "quantitative risk" is defined as the product of a points coordinates when the axes are interpreted quantitatively, for 
example, frequency $\times$ severity. The risk Matrix adopted for the Risk register it's there to provide a rough discrete (ordered categorical) approximation to a more detailed, but not readily available underlying quantitative relation between likelihood and severity of scenarios (Risk = probability $\times$ consequence). Cox (2008) suggests that such an intuitive interpretation of the risk matrix as an approximation to an underlying quantitative model can only be sustained if the risk matrix, at a minimum, "discriminate reliably between very high and very low risks, so that it can be used as an effective screening tool to focus risk management attention and resources". This requirement is named by Cox as the "principle of weak consistency between the ordered categorisation of risks provided by the matrix and the ranking of risks by an underlying quantitative formula". If this principle is respected all risks in the top qualitative category are quantitatively larger than all risks in the lowest qualitative category, and "the risk matrix can discriminate reliably between at least some risks, even though it does not require quantifying the probability and consequence attributes" (Cox, 2008). So it can be used as screening tool, which in the risk register is the main practical uses of the adopted risk matrix. The use of the matrix is mainly to rank individual risks to allow a better appreciation of their (relative) importance and seriousness. However as pointed out by Ale et al. (2015) any discussion on the individual acceptability of each risk needs to be done on a case by case basis and generalisations shouldn't be allowed unless the risk estimates associated to the scenario under analysis are supported by further quantification method.

The $5 \times 5$ risk exposure matrix used categorises risks as:

- $\quad$ Red (14-20; Unacceptable risk. Detailed action plan required to reduce to Medium or Low, management involved and periodically informed)

- $\quad$ Orange (12-14; Apply immediate controls to reduce risk Action plan and responsibility to be specified to reduce to Medium or Low risk.)

- $\quad$ Yellow (6-10; Apply judgment: Specify mitigation responsibility and plan mitigation to reduce to Low)

- $\quad$ Green (1-5; Acceptable risk: Monitor and manage by 
routine procedures to minimise or close off the risk.)

- $\quad$ The use of four categories matches industry common practice.

\subsubsection{Hazard categories}

The risk register should monitor technical and non-technical hazards in order to fully represent potential risks. In this case, ISO 17776 in combination with an analysis of the hazards and risks already captured within the company was used to provide a framework of hazards within the risk register. The initial framework is shown in Table 5. This will allow the company to systematically review each hazard category and modify the classification system for new and emerging hazards after during the testing period and after if needed.

Table 5. Hazard categories.
Category Examples
Technical Specific hazards relating to equipment - e.g. turbine:
mechanical, vibration, aging, lubrication, pressure, etc.;
boiler: piping, valves and drains, burner; structural integrity, etc.
Process Hazards relating to the process, e.g. leaks, explosive or flammable materials, dust emissions, flooding, high/low pressure, high/low temperature, etc.
Work activities Hazardous activities, e.g. working at height, manual handling, working with vehicles, lone working, working near water, traffic management
Work Hazards relating to the physical plant, e.g. ground conditions environment (slips, trips and falls), sharp surfaces, hot/cold surfaces, noise, confined spaces, blocked fire escapes, etc.
External All external hazards, including adverse weather conditions, natural hazards (e.g. seismic activity, lightening, radiation), external accidents (adjacent plants, aircraft), terrorism, 3rd party threats, etc.
Behavioural Hazards resulting from individual (inappropriate) behaviours, e.g. intoxication, inappropriate use of tools, bullying and 
harassment, interference with safety mechanisms, peer pressure

Organisational Hazards relating to poor support from the organisation or inappropriate organisational pressures, e.g. inadequate training, poor organisational change management, mismatch of work to capabilities, lack of fatigue management, medical unfitness, poor procedures, etc.

Environmental Hazards relating to the environment, e.g. spills and leaks, environmental noise, hazardous emissions, etc.

Financial Hazards relating to finance, e.g. staff costs, contractor costs, taxes, material availability, stock management

Project Hazards relating to projects, e.g. human resource availability, management plant performance, project performance, stakeholder management, lifecycle management, contractor management

Following the series of workshops with each station using the risk register solution, the data within the risk register was analysed to determine how well the hazard and risk categories represented the data. The main finding was that the hazard category was too large (109 hazard categories), and not all codes were in use (51 hazard categories un-used). The workshops had revealed some confusion about which codes to use, and the analysis revealed that the codes were not mutually exclusive. Also the workshops revealed the necessity to add extra categories more appropriate to newer technologies (e.g. wind power). The data was re-coded to determine a reduced set of hazards for use. This reduced the overall number of hazard codes from 109 to 72 .

\subsection{Assessment of mitigations}

Existing and planned mitigations for each risk are captured and are classified using the following scheme:

- $\quad$ Discontinuing the activity;

- $\quad$ Remove/substitute the hazard;

- $\quad$ Actions to reduce the impact and/or probability of the risk;

- $\quad$ Transferring the risk (e.g. insurance); 
- $\quad$ Retaining and monitoring.

Furthermore the users are asked to provide a self-assessment from 1 to 5 to rank the effectiveness of the control measures taken. It is important to provide an accurate (though by nature subjective) account of how much the risk has been reduced by the actions taken. In many cases, even a significant effort does not greatly reduce the risk due to factors beyond the mitigation owner's control. At other times, even small or simple steps make a visible difference in risk reduction. Therefore, this is not a measure of quality of the mitigation but rather the risk complexity or influence (supporting/neutral/hostile) of the risk centre's environment. The scores for the Current Mitigation Effectiveness are shown in Table 6.

Table 6. Mitigation effectiveness ratings.
Rating Meaning
$1 \quad$ Not effective
$2 \quad$ Minimal effect
3 Moderate effectiveness
$4 \quad$ High effectiveness
5 Fully effective mitigation removing the immediate risk and reducing it in future

2.6. The interim implementation

The interim development of the risk Register in the company took the shape of a SharePoint solution on the internal website of the company.

This interim solution was selected as it allowed a low cost internal development of a prototype to test the stability of the data structure proposed in view of channelling more advanced functional requirements for a web based application capable of supporting also the risk reporting and data analysis needs. Figs. 2, 3, 4 reports three screenshot of the interim development. 
Risk registers: Structuring data collection to develop risk intelligence - ScienceDirect

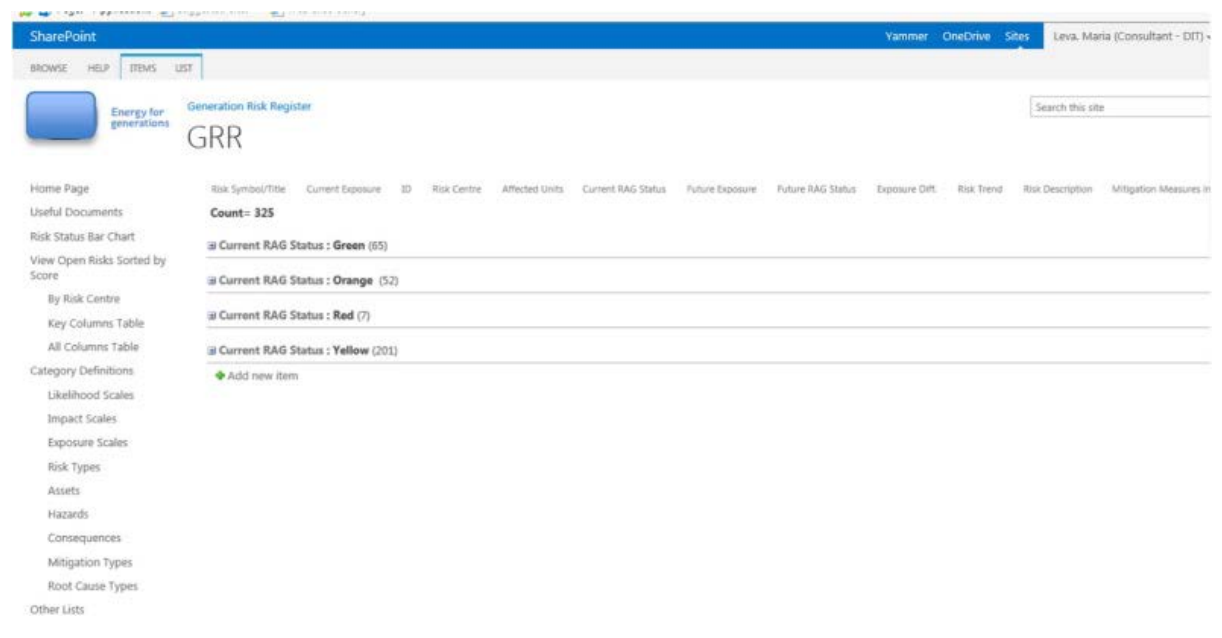

Download high-res image (103KB) Download full-size image

Fig. 2. Menu page for Interim implementation in Sharepoint in the company.

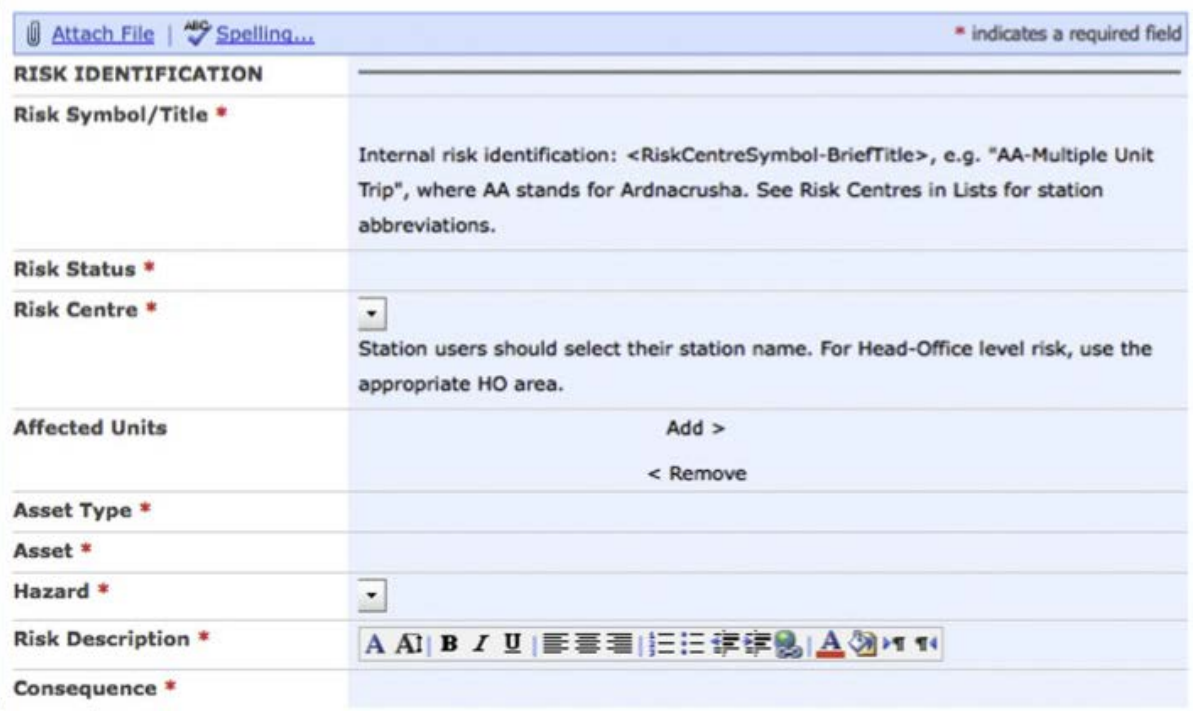

Download high-res image (163KB) Download full-size image

Fig. 3. input page for Interim implementation in Sharepoint. 


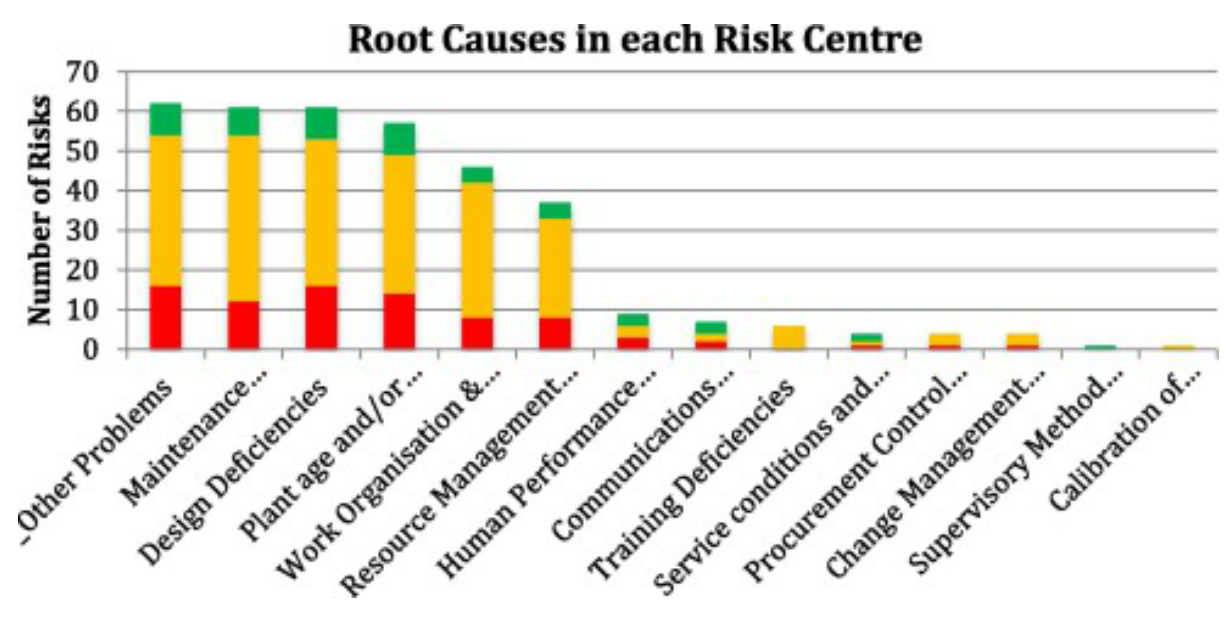

Download high-res image (295KB) Download full-size image

Fig. 4. Overview of common root causes for the hazards reported in the risk register shared across multiple stations.

\subsection{Risk management process}

The risk management process around the Risk Register consists of three main parts:

1. Monthly Risk Update - at station level;

2. Quarterly Risk Validation - involving both station level and organisation-level risk specialists;

3. Quarterly Risk Reporting - at organisation and senior management level - involving Risk Reporting Managers and members of the Senior Management Team.

The process ensures that the report is fed back to station risk specialists by the Generation Risk Reporting Manager, so that the most up to date risk information is circulated evenly and retained within the organisation for subsequent re-use.

Several KPI have been identified to monitor the use and content of the risk register and these are reported in Table 7.

Table 7. KPI identified to monitor trial implementation of the Risk

\section{Register.}




\begin{tabular}{|c|c|c|c|}
\hline No. & KPI & $\begin{array}{c}\text { Frequen- } \\
\text { cy }\end{array}$ & Definition \\
\hline 1 & $\begin{array}{l}\text { Percentage of Risks Updated } \\
\text { within Last } 90 \text { Days }\end{array}$ & Monthly & $\begin{array}{l}\text { Red: Less than } 75 \% \text { of record } \\
\text { Amber: At least } 75 \% \text { of recor } \\
\text { Green: At least } 90 \% \text { of recorc }\end{array}$ \\
\hline 2 & $\begin{array}{l}\text { Average Mitigation } \\
\text { Effectiveness (Self-Assessed) }\end{array}$ & Monthly & $\begin{array}{l}\text { Red: score }<2 \\
\text { Amber: } 2<=\text { score }<4 \\
\text { Green: } 4<=\text { score }<=5\end{array}$ \\
\hline 3 & $\begin{array}{l}\text { Mitigation/Control } \\
\text { Measures in Place and } \\
\text { Functioning (Audited) }\end{array}$ & Quarterly & $\begin{array}{l}\text { A manual KPI based or } \\
\text { management audits comple } \\
\text { station annually to rev } \\
\text { measure application defi } \\
\text { proportion of satisf } \\
\text { requirements: } \\
\text { Red: less than } 75 \% \text {. } \\
\text { Amber: less than } 90 \% \\
\text { Green: } 90 \% \text { or more. }\end{array}$ \\
\hline 4 & $\begin{array}{l}\text { Number of Red and Amber } \\
\text { Risks }\end{array}$ & Monthly & $\begin{array}{l}\text { This is a statistic rather than } \\
\text { indicator. The focus is on t] } \\
\text { month trend. }\end{array}$ \\
\hline 5 & Number of Open Risks & Monthly & $\begin{array}{l}\text { This is a statistic rather thar } \\
\text { indicator. The focus of this : } \\
\text { the month-to-month trend. }\end{array}$ \\
\hline
\end{tabular}

As part of the rollout, the stations were provided one to one training in the form of a face to face meeting or a teleconference on the new tool and asked to input their risk and during the first two quarters. Following this a risk review workshop was organized in each station to review their risk and collect feedback on the tool.

\section{Case study evaluation}

The key points for the validation of the Risk Register were:

1. How well the data structure supports the identification and categorisation of risks;

2. How the rating scheme is used to manage and prioritise risks (facilitating the risk management process);

3. The attitude of the stations towards use of the final tool, including their willingness to populate data;

4. The perceived effectiveness and efficiency of the tool across the different stakeholders;

5. Assessment against the high level requirements.

The feedback was collected in two ways: 
A. Through a survey answered by a sample of the main asset specialists in each station in charge of reporting towards the generation risk register

B. Through the feedback collected in the annual risk review workshop held in each station during first quarter of 2014 and 2015

\subsection{Data structures}

The data structure was finally able to provide an harmonised view of the main hazardous scenarios shared across the business in various stations (as shown in the example reported in Fig. 4).

A key finding from the implementation of the risk register is that the local business units cannot actively manage a fully comprehensive set of risks facing their area of the business, as these can quickly become overwhelming and the risk register becomes encumbered by low level risks that are routinely effectively managed through existing standards and procedures. The risk register should contain all risks being actively managed - those which require additional investment or further analysis, and those which have a high degree of uncertainty associated with them. Low level risks or risks managed on an on-going basis through established business process will not benefit from the additional scrutiny of being on the risk register, and may serve to obscure more critical risks. However, the set of hazards should be as comprehensive as possible, in order to prompt entries and help with analysis of the data held in the register. Some flexibility in the hazard categories may be necessary to allow them to be adjusted and expanded according to business needs.

A strong rating scheme for likelihood and severity of each documented risk is the best method currently available for ensuring consistency within the risk register. The scales should be applicable across the business, sensitive enough to collect useful information on the smaller business units but relevant enough to allow comparison across business units and prioritization of the business risks. However, the nature of risk assessment is speculative and sufficient empirical data is rarely available to accurately quantify either the likelihood or severity 
of foreseen risks. Such data might be collected over time through data mining accident and incident databases, as well as the risk register itself, but this is currently beyond the ability of most organisations. The rating is therefore somewhat subjective, and even using a clearly defined scale one user may be inclined towards higher ratings than another. The differences may not be great (one point either direction), but on a five point scale this can make the difference between an amber rating (e.g. 12) or a red rating (e.g. 16). As well as the unintentional variability introduced through subjectivity, some business units might also intentionally increase their ratings to theoretically possible but unrealistic values in order to highlight an issue in their area and attract investment to address it. It is therefore necessary to include a review step in the business process underlying the risk register. This review process may have several aims, but one should be the consistent rating of risks across stations. As issues emerge, additional guidance and modifications can be added to the scales to improve the reliability of the ratings, and any changes should be fed back to users regularly to help improve consistency.

\subsection{Rating scheme}

The rating scheme is well-used and appears to support efficient prioritisation of the risks at station level. Some minor changes were made over the course of the implementation to clarify language and consistency.

The impact categories may need to be revised as the risk matrix is now implemented and used across various levels of risk exposure estimates also in asset management. The proposal is to harmonize in the company the matrix used for the technical risk review process for assets. This will probably imply a revision of the financial scale to get values more granular and therefore sensitive towards lower end of the scales able to capture distinctions that individual stations may consider more aligned towards their ranges of financial implications.

\subsection{Station attitudes}

Initial feedback from the stations has been predominantly positive and uptake has been strong; all stations have contributed risks to the register and regularly update their risks. 
Feedback on the coding scheme was collected during the station workshops and used to iteratively improve the risk register during the early implementation period.

More formal collection of feedback from stations was achieved via a survey, with seven responses (representing almost $60 \%$ of the station managers). The survey determined that use of the Risk Register had improved from between quarterly and yearly for the old 'Top 10' format to between monthly and quarterly for the new Risk Register. Fig. 5 describes the overall perception of benefits of the Risk Register ( 1 = strongly disagree; 5 = strongly agree). The majority of anticipated benefits have been achieved in the eyes of the frontline users, but there is room for improvement in terms of supporting periodic reporting in terms of KPIs, the consequence rating scale, and accounting for short term emerging risks.

\section{Risk Register Benefits}

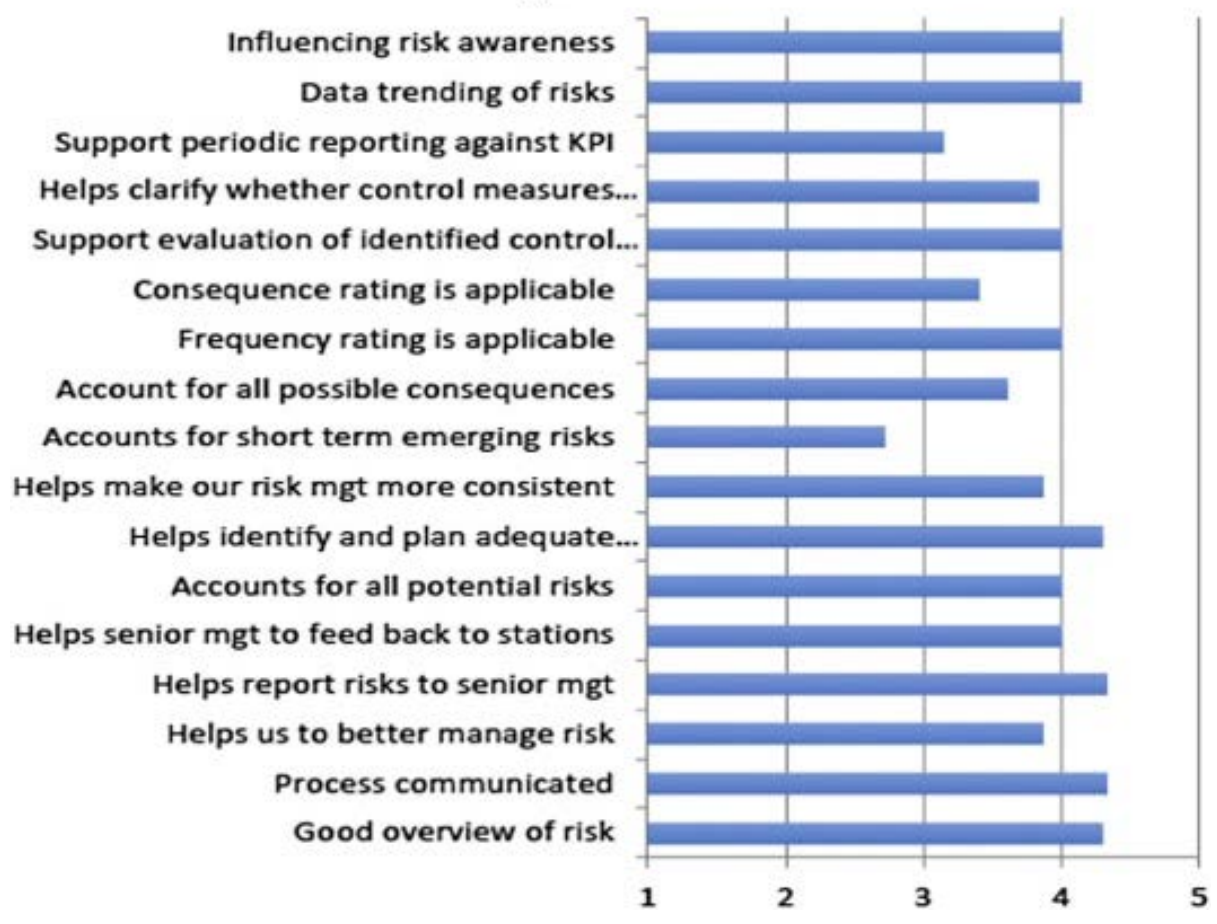

Download high-res image (178KB) Download full-size image

Fig. 5. Results of evaluation of questionnaire responses from stations on overall perception of benefits of the Risk Register ( 1 = strongly disagree; 5 = strongly agree).

Specific benefits listed by participants included the consistency 
of the data structures, ease of use and ability to overview information and drill down as required, and the use of the tool to provide assurance of correct risk management.

The interim development in Sharepoint was evaluated and deemed to be not very user friendly as the feedback collected on the IT tool was generally less positive than that collected about the structure of the Risk Register itself, particularly in terms of efficiency. It indicates that a dedicated IT platform may be more beneficial than the Sharepoint solution introduced as a dedicated tool can be more tailored to specific user needs. Additionally, further data analysis could be achieved within a Risk Register tool, whereas data must currently be exported from the interim solution developed in Sharepoint for further analysis.

\subsection{Comparison against requirements}

The solution currently implemented and the related risk management process have addressed the majority of the identified high level requirements, as described in Table 8. Only HLR6 was not fully met, in that the risk register provides a single point for the documentation of risks but this is not a fully dynamic process, relying on manual data entry and review at fixed periods.

Table 8. Assessment against HLRs.

\section{ID Description (high level requirement)}

HLR1 Create a comprehensive and consistent risk management process.

$\rightarrow$ Three new processes were devised - for updating, validation and reporting of risks. Three tiers of stakeholders were defined. Roles of responsibilities were defined. Best practices embedded

HLR2 Reports/matrices shall provide an update of the risk levels within the business at a particular moment of time and take into account possible short term emerging risks i.e. weather extremes, equipment type faults, internal or external incident investigations, etc.

$\rightarrow$ The new central Risk Register caters for different types of risks, based on multiple inputs

HLR3 The risk management system shall ensure that all potential hazards 
are identified and assessed.

$\rightarrow$ The Risk Register captures and validates information on potential hazards and associated risk likelihood, impact and exposure

HLR4 The risk management system shall ensure that adequate control measures are put in place.

$\rightarrow$ The Risk Register captures information on Existing Mitigations and Additional Mitigations

HLR5 The risk management system shall ensure that control measures remain effective in the management of each risk.

$\rightarrow$ Previously entered mitigations are reviewed and scrutinised as part of the processes around the Risk Register

HLR6 All risk information shall be held in a single risk register which encompasses all business risks into a single dynamic source.

$\rightarrow$ The Risk Register is a central repository for all risks across the entire business, however it is manually updated and dynamism is limited

HLR7 Periodic hazards and risk reviews shall be carried out.

$\rightarrow$ New Risk Management Processes have been mapped: Monthly Risk Update at station level, Quarterly Validation at Generation level and Quarterly Reporting at SMT level.

In particular, the process prescribes that all risks are reviewed at least once a month, and updated their details and mitigation plans modified at least:

Once a quarter (for high and medium scored risks);

Once a year (for low risks)

HLR8 All hazards shall be identified, and periodic hazards and risk reviews shall be carried out.

$\rightarrow$ Already covered by HLR7

HLR9 Key performance indicators shall be developed to ensure that the key hazards have been identified and assessed, that all business risks are regularly reviewed, and that control measures are in place and effective in reducing risks to a tolerable level.

$\rightarrow$ Tolerable risk levels were defined according to a new standard Risk Matrix as the "Green" (Low) score 1-5 in the 1-25 compound risk exposure scale

HLR10 The system shall be fully aligned to the company's strategy, with strong and positive management leadership thus ensuring that the business risks are understood from the board room to the control 
room, with real time risk management decision making and a comprehensive risk assessment process which systematically identifies, assesses and appropriately manages risk from the organisation operations.

$\rightarrow$ Detailed process and system guidelines were prepared and distributed to stakeholders and system users to ensure clear understanding and appropriate buy-in

HLR11 A single company procedure for measurement and reporting of risk shall be delivered and tolerable risk shall be clearly defined, understood and utilised, thus meeting a fundamental requirement of Process Safety.

$\rightarrow$ [Missing information on how this was met]

\section{Extending the concept of a company's risk register}

The Risk Register in the case study concluded with the implementation of a system that generates a single large table of risks for the business. This approach allows for consistency of the register's data as all stations use the same set of column dropdown values, helping to structure their inputs and analysis. For simplicity, each risk is detailed in one complete record including categorisation, pre- and post-mitigation scoring and current and planned mitigating action. This system effectively serves its stated purpose (as shown against the high level requirements) however it has also served to highlight shortcomings of the Risk Register concept, in particular in relation to developing a solution better able to handle knowledge management capabilities for the following aspects:

(1) Aggregation of risks from station level to central level;

(2) Support controls over mitigation measures at station and central level;

(3) Support better data based estimates for likelihood of scenarios based on accident data;

(4) Integration with company asset register;

(5) Support a better link with workflow around risk communication;

(6) A potential link with day to day operational practice. 
Each of these potential improvements are described in the following sections.

\subsection{Aggregation of risks from station level to central level}

The rating scheme of the risks based on the risk matrix is currently used for the purpose of sorting and screening, while the risk register needs to include a further criteria to estimate corresponding classes of monetized risk values to be able to aggregate risks that are in common across multiple stations with different likelihood and exposure in the various impact categories. The risk matrix score is in fact provided ont eh basis of qualitative scales. Qualitative scales are themselves inherently flawed when it comes to aggregate risk. When using qualitative scales, it is very difficult to say how to compare 2 High risks with 3 Medium risks, or how high is a High risk. This is a primary motivation for trying to monetize rating scales.

This is necessary to identify the top ten hazard scenarios relevant across the entire organisation as a whole to facilitate better monitoring by senior management. This will enable hazard categories to be sorted across different stations on the basis of sum of equivalence of economic value of impact multiplied by likelihood for each event category.

The system can ultimately rank risks across equivalent economic ranges for Cat 1 (red) Cat2 (orange) and Cat 3 (yellow) and Cat 4 (green) economic ranges. A trial implementation of this approach has been achieved in the case study organisation. Table 9 reports an example of the resulting aggregated Top Ten issues obtained using the monetized categories. 


\begin{tabular}{|c|c|c|c|c|c|}
\hline ref & top 10 scenarios & $\begin{array}{l}\text { Number of } \\
\text { affected } \\
\text { centres }\end{array}$ & $\begin{array}{l}\text { Monetized } \\
\text { risk class }\end{array}$ & $\begin{array}{l}\text { Max } \\
\text { CURRENT } \\
\text { EXPOSURE }\end{array}$ & $\begin{array}{l}\text { Mar } \\
\text { FU1 } \\
\text { EXF }\end{array}$ \\
\hline 1 & $\begin{array}{l}\text { Org. Conditions } \\
\text { Inexperienced workers }\end{array}$ & 9 & Cat 1 & 20 & 12 \\
\hline 2 & Fin. - Plant performance & 12 & Cat 2 & 16 & 12 \\
\hline 3 & $\begin{array}{l}\text { Tech. - Mechanical integrity } \\
\text { \& design flaws }\end{array}$ & $\mathrm{y}_{12}$ & Cat 2 & 15 & 12 \\
\hline 4 & Tech. - Aging & 11 & Cat 2 & 15 & 9 \\
\hline 5 & Tech. - Reliability & 12 & Cat 2 & 12 & 12 \\
\hline 6 & $\begin{array}{l}\text { External Safety - Advers } \\
\text { weather }\end{array}$ & 8 & Cat 2 & 16 & 10 \\
\hline 7 & Fin. - Market & 12 & Cat 2 & 16 & 12 \\
\hline 8 & $\begin{array}{l}\text { Regulatory - Breach } 0 \\
\text { operating license }\end{array}$ & of 8 & Cat 3 & 16 & 9 \\
\hline 9 & $\begin{array}{l}\text { Regulatory - Civil or } \\
\text { criminal litigation }\end{array}$ & $\mathrm{r}_{1}$ & Cat 3 & 16 & 1 \\
\hline 10 & Fire & 9 & Cat 3 & 12 & 10 \\
\hline
\end{tabular}

\subsubsection{Aggregation of risks for safety related outcomes}

The tool can now enable to query all the events leading to possible fatality scenario and the initial assumption is that the overall probability of one fatality in the year is the sum of all the individual entries potentially leading to single or multiple fatalities can be considered together with their associated expected value of their likelihood range. If this sum leads to a likelihood above the max value assumed for category 3 in the likelihood scale in case of single fatality and above the values covered by categories 2 in the likelihood scale for multiple fatalities it is flagged to the management team as a company wide inadmissible exposure and it triggers the need to safety intervention. It also highlights all the entries contributing towards that risk.

\subsection{Support controls over mitigation measures at station and central level}

A second issue that the introduction of the risk register in the organisation brought to the fore is how can the tool better support the workflow connected with ensuring appropriate control measures are in place for each risk in each stations and how to share the knowledge about the most effective measures identified so as to foster reinforcement of best practices across different stations. 
As described in Section 2.5, information on the effectiveness of mitigations is currently captured in a free text space and via a subjective rating. The documented mitigation measures are subsequently audited in each station through the internal risk management audit scheme (which foresees one internal audit to be carried out in each station quarterly) and the current system in place used for accident and inspection reporting is used to document the findings of the audit, where the internal auditor has to confirm whether or not the mitigation measure is in place and how effective it has been found to be. Currently a manual $\mathrm{KPI}$ is calculated based on the results of the four risk management audits completed in each station annually to review control measure application defined as a proportion of satisfied audit requirements.

A proposed improvement in risk register would enable the tool to document and support the workflow connected with monitoring and reviewing mitigations through the audit system. This would result in a more accurate assessment of the effectiveness of the mitigations, rather than relying on a subjective effectiveness rating.

4.3. Likelihood and updates of events from accident database The likelihood ratings are also currently subjective, and hence open to bias (either positive or negative). On the basis of the events collected in the accident and incident database of each station it may be possible to inform less subjective estimates for the likelihood ranges of the scenarios to be documented in the risk register.

In common with many other organisations, the company in this case study currently has a different IT system for documenting and classifying accidents and incidents. On the basis of the entries to this system, it is possible to estimate for each hazard category a corresponding rate based on the past six years of reporting history at company level, which in turn can provide the basis to estimate the average number of events per year and use that as a designated rate parameter $(\lambda)$ in a Poisson distribution. Therefore the system could automatically suggest the probability of observing $\mathrm{k}$ events in a year using the Poisson formula: 
To enable this functionality, the hazard categories collected in the existing accident and incident reporting tools and those used by the risk register will have to be harmonised. Table 10 reports a snapshot of some of the events that can be collected from the incident reporting systems.

Table 10. Example of incident data.

\begin{tabular}{|c|c|c|c|c|}
\hline ID & Type & Status & Description & $\begin{array}{l}\text { Occurre } \\
\text { Date }\end{array}$ \\
\hline 11283 & $\begin{array}{l}\text { Process } \\
\text { Safety: } \\
\text { Operational } \\
\text { Incident }\end{array}$ & $\begin{array}{l}\text { Incident } \\
\text { Closed }\end{array}$ & $\begin{array}{l}\text { Hydrogen System - Operations } \\
\text { depressurising hydrogen line } \\
\text { after top ups }\end{array}$ & $\begin{array}{l}\text { 29-Jan- } \\
2015\end{array}$ \\
\hline 11284 & $\begin{array}{l}\text { Process } \\
\text { Safety: } \\
\text { Operational } \\
\text { Incident }\end{array}$ & $\begin{array}{l}\text { Incident } \\
\text { Closed }\end{array}$ & $\begin{array}{l}\text { Hydrogen System - new skid in } \\
\text { compound does not have } \\
\text { "Excessive flow" safety shut off } \\
\text { value }\end{array}$ & $\begin{array}{l}\text { 29-Jan- } \\
2015\end{array}$ \\
\hline 11285 & $\begin{array}{l}\text { Process } \\
\text { Safety: } \\
\text { Operational } \\
\text { Incident }\end{array}$ & $\begin{array}{l}\text { Incident } \\
\text { Closed }\end{array}$ & $\begin{array}{l}\text { Hydrogen - value installed that } \\
\text { allows the draining of the line to } \\
\text { the station should be disabled or } \\
\text { removed }\end{array}$ & $\begin{array}{l}\text { 29-Jan- } \\
2015\end{array}$ \\
\hline
\end{tabular}

4.4. Integration with critical asset registers (CAR)

A component or system in the company is defined as Safety Critical if its function is to prevent an abnormal condition escalating into a major incident (ISO 55001, 2014). Within the case study organisation, a major incident is defined as an occurrence (including in particular a major emission, fire or explosion) resulting from uncontrolled developments in the course of the operation of plant, leading to life changing serious injuries or loss of life, serious danger to the environment, (immediate or delayed), extensive damage to property and plant, inside or outside the station. To ensure best practice in terms of safe and efficient asset management the company 
adopted the industry standard PAS 55 issued by the Institute of Asset Management and published by the British Standards Institution in 2004 (PAS 55:2008). The standard provides guidance across several aspects of good asset management, from lifecycle strategy to everyday maintenance (cost/risk/performance). It was then transitioned to ISO 55000 an international standard covering management of physical assets.

The company currently uses a common structured spreadsheet as a critical asset register (CAR) for all stations. The tool is held in a spreadsheet format stored in an integrated on line shared location, with a separate workbook for each station and accessible to central asset specialists.

The tool reports the minimum required information for each station and calculates a risk rating for each based on the status, but it does not actually detail the failure modes and their consequences upon which the risk rating is based. The risk register fills this gap. If the CAR tool were to support a better identification of hazards associated to each piece of equipment in alignment with what is required by the risk register, the tool could in itself cover all the requirements to also serve the purpose of assert risk register for the company as a whole and for each station considering the technical asset risks. This in turn will lead to move also the current CAR towards a web based and integrated knowledge management IT solution that can be considered a module of the risk register (or be able to export data directly into it).

4.5. Support a better link with workflow around risk communication

One of the main issues collected through the initial feedback is that the Risk Register tool as implemented in the case study did not fully support an actual engagement and two way communication loop between stations and central asset specialist and or stations and central management. Despite being a requirement from the outset, the ability to provide meaningful two-way communication is limited by the Sharepoint format, which is primarily a data repository. The Risk Register works more as a one-way communication whereby the stations 
communicate their risk centrally but do not receive any actual feedback or updates about possible central improvements or best practices around mitigation strategies for their risk and how they are managed or shared similarly elsewhere.

To be able to do so, a more powerful web-based IT solution could support the monthly and quarterly reporting/communication both at station level (from station to central location) but also from central level to station level, effectively supporting revisions of those risks by either asset specialist or by Management committee meeting. Figs. 6 and 7 report the overview of the two-way communication flows that should be supported.

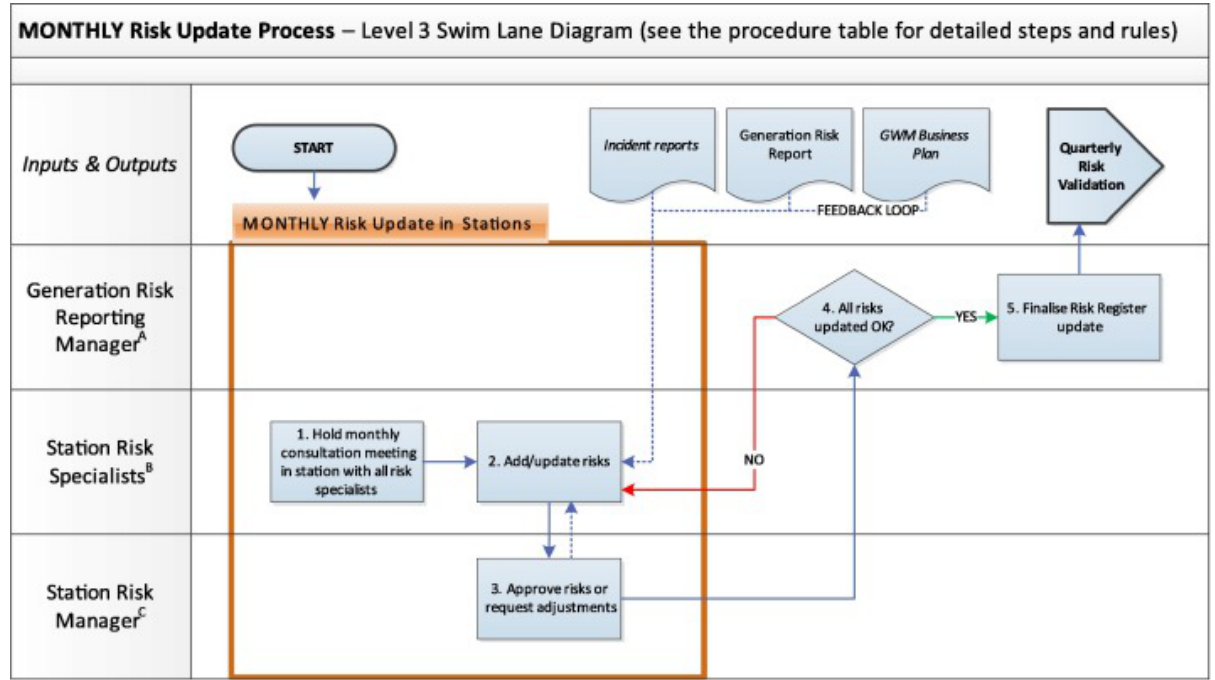

Download high-res image (415KB) Download full-size image

Fig. 6. Communication flow for monthly risk review process. 


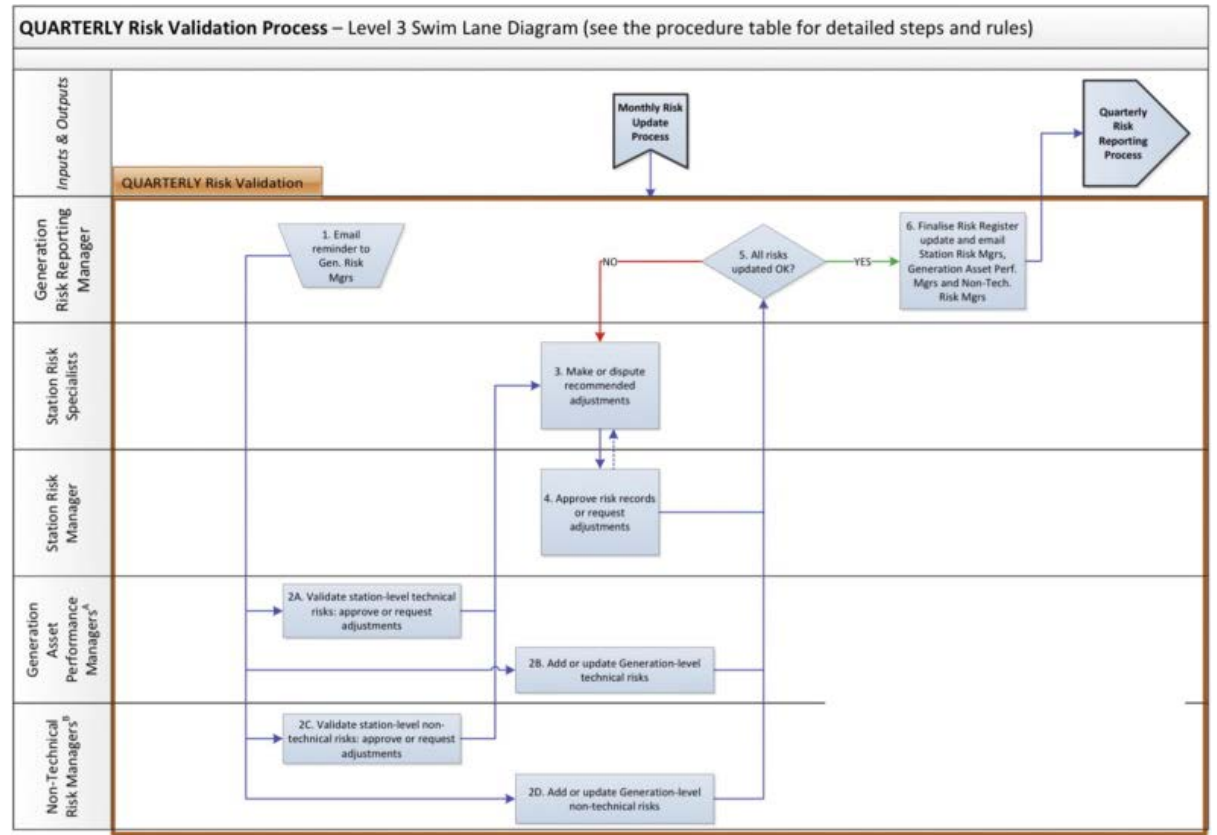

Download high-res image (200KB) Download full-size image

Fig. 7. Communication flow for quarterly risk review process.

4.6. A potential link with day-to-day operational practice

As part of the process safety improvement plan of the company there is an on-going effort to support consistent and efficient transfer of safety, operational and commercial information between operational shifts to reduce the potential for misunderstanding or the non-reporting of technical or commercial events, issues, status or risks though a computerised logging system to improve the management and communication of critical operating information connected to shift handovers. The scope is to achieve the following benefits:

- Improved safety of personnel and plant

- Improved environmental performance

- Improved commercial performance

- Standardisation of plant operation

- Regulatory compliance

- $\quad$ Operation staff training

- $\quad$ Reduction in duplicated reporting

- Optimisation and performance of existing systems and 
processes.

In addition to the above improvements, Process Safety improvements will further require recording of operational abnormalities including: demand on safety systems, plant upsets, insufficient operating discipline, procedures not followed, near misses, etc. as lower tier incidents, which can be then be analysed and improved on. This can also lend itself to a way of improving a two way live feed between an operational log and the risk register as the risk register can provide an overview of the main company risk scenarios relevant for operations but on the other end the operational log can provide info to verify how those risks may actually affect operational practices and introduce new potential risks on the basis of observed deviations from recommended design ranges. If the two systems were able to exchange information automatically it would reduce the amount of information to be manually transferred or input in both.

\section{Conclusions}

This paper has described the development and implementation of a company wide Risk Register system and process in an electricity generating business. Although largely successful against the key requirements, the implementation has uncovered areas for future development that can improve risk management further.

The considerations discussed in the previous section would suggest that the best way to further implement the knowledge management capacity of the risk register is by integrating new functions into the current IT system used in the company for accident incident and near miss reporting by providing a further elements for hazard identification (not retrospective in nature) and to follow up the risk review process and the monitoring (audit) for each station and at the same time facilitating the sharing of best practices and information across the multiple locations (as a web based application).

The framework reported in Fig. 8 is a vision of future possibilities for safety and risk management building on the kinds of risk register reported within the case study. This vision describes a 
situation where existing systems containing relevant information (e.g. asset registers, incident databases, audit system, etc.) are linked to the risk register. Ideally this link would be automatic to reduce manual processing time and/or duplication of effort. Harnessing this information allows a comprehensive and dynamic representation of risk to be developed in the risk register. This information must be reviewed and acted upon at both a local level, to ensure front line risk management, and at a central level to ensure company wide measures are implemented where necessary. Utilising the inputs and modifications from expert reviews, the central Risk Register tool can identify risk priorities and calculate KPIs for risk management across the organisation, thus enabling effective and efficient monitoring and feedback by senior management.

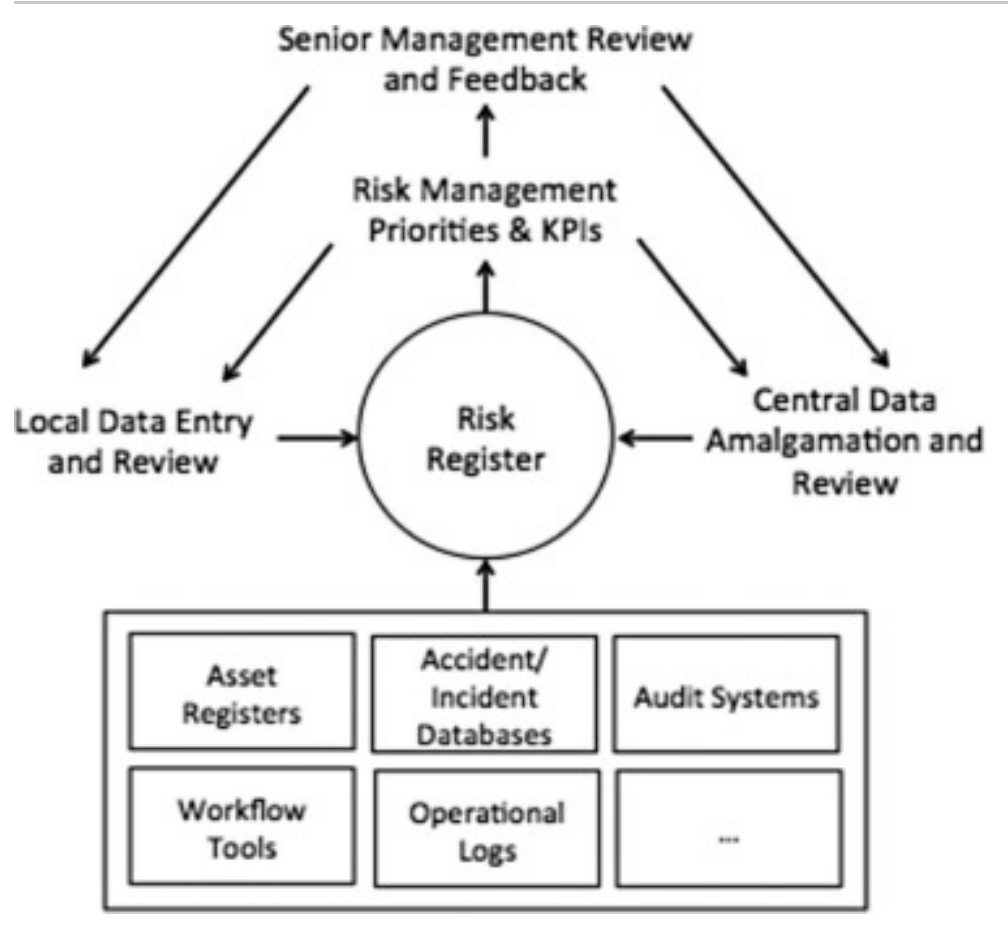

Download high-res image (85KB) Download full-size image

Fig. 8. Agenda for Risk register integration into Process Safety

Framework tools.

Further research will focus on furthering this vision, and providing concrete steps to achieving risk intelligence. The initial research focused on identifying what data already exists, and what information can be generated from that data and has already identified the following elements: 
(1) Need to integrate with existing IT tool used for accident and incident and process safety events

(2) Need to integrate with tool used to collect information and manage workflow from Audits in each station and collect information about effectiveness of Mitigation measures

(3) The risk register needs to support better at station level the workflow around the periodic status updates and review of the main company risks and the feedback between stations and central management review of the same risks, especially when central mitigation strategies for aggregated risks may be more effective than local mitigation measures only.

(4) Need to integrate with periodic review of operational logs to keep track of how certain risk are evolving in day to day experience

(5) The risk register duplicates some of the information the company already collects as part of the Critical asset register. If the critical asset register were to facilitate the collection of the main hazard categories and scenarios associated to asset reporting high risks it would facilitate the establishment of a asset based risk repository that could be generated already as part of the information collected at stations level in the asset register

Test cases for each of the above elements will be detailed to identify in practice the feasibility of the IT integration and build a concrete business case, with a comprehensive cost-benefit analysis, to highlight the insights and benefits that can be achieved from this information.

\section{Acknowledgements}

This publication has emanated from research supported in part by a research grant from Science Foundation Ireland (SFI) under Grant Number 14/IFB/2718 and by the EU FP7 project 'Total Safety Management for Critical Activities' (TOSCA; see www.toscaproject.eu) under Grant Agreement FP7-NMP-2012SMALL-6-310201. The authors wish to acknowledge the assistance of Sebastian Manka and Yilmar Builes. 


\section{References}

Ale et al., 2015 B. Ale, P. Burnap, D. Slater

On the origin of PCDS - (probability consequence diagrams)

Saf. Sci., 72 (2015) (2015), pp. 229-239

Article PDF (3MB)

Balfe et al., 2014 N. Balfe, M.C. Leva, B. McAleer, M. Rocke

Safety risk registers: challenges and guidance

Chem. Eng. Trans., 36 (2014), pp. 571-576

Brown, 2004 A.S. Brown

Finding the hidden risk with medical devices: a risk profile tool

Qual. Prim. Care, 22 (2) (2004), pp. 137-140

Cooke-Davies, 2002 T. Cooke-Davies

The "real" success factors on projects

Int. J. Project Manage., 20 (2002), pp. 185-190

Article PDF (134KB)

Cox, 2008 L.A. Cox

What's wrong with risk matrices?

Risk Anal., 28 (2) (2008), p. 2008

Crossland et al., 1998 R. Crossland, C.A. McMhahon, J.H. Simms Williams

Survey of Current Practices in Managing Design Risk

Design Information Group, University of Bristol (1998)

De Zoysa and Russell, 2003 De Zoysa, S., Russell, A.D., 2003. Structuring of risk information to assist in knowledge-based identification of the life cycle risks of civil engineering projects. Paper presented at the 5th Construction Speciality Conference of the Canadian Society for Civil Engineering, Moncton, Canada, 4-7 June, 2003.

Dunović et al., 2013 I.B. Dunović, M. Radujković, Vukomanović

Risk register development and implementation for construction projects

Gradevinar, 65 (1) (2013), pp. 23-35

Filippin and Dreher, 2004 K. Filippin, L. Dreher

Major hazard risk assessment for existing and new facilities

Process Saf. Prog., 23 (4) (2004), pp. 237-243

Hasle et al., 2009 J.R. Hasle, U. Kjellen, O. Haugerud

Decision on oil and gas exploration in an Arctic area: case study from the Norwegian Barents Sea 
Saf. Sci., 47 (2009), pp. 832-842

Article PDF (1MB)

ISO 55001, 2004 ISO 55001:2004. Asset Management. BSI Group (retrieved 10 February 2014).

ISO 17776, 2002 ISO 17776

Petroleum and Natural Gas Industries - Offshore Production Installations - Guidelines on Tools and Techniques for Hazard Identification and Risk Assessment International Organisation for Standardisation, Geneva (2002)

Kontogiannis et al., this issue Kontogiannis, T., Leva, M.C., Balfe, N., this issue. Total Safety Management: Principles, Processes and Methods.

Kutsch and Hall, 2010 E. Kutsch, M. Hall

Deliberate ignorance in project risk management

Int. J. Project Manage., 28 (2010), pp. 245-255

Article PDF (226KB)

Leonard, 1995 J.B. Leonard

Assessing risk systematically

Risk Manage., 42 (1) (1995), pp. 12-17

Leva et al., 2012 M.C. Leva, R. Pirani, M. De Michaela, P. Clancy

Human factors issues and the risk of high voltage equipment: are standards sufficient to ensure safety by design?

Chem. Eng. Trans., 26 (2012), pp. 273-278

Leva et al., 2014 M.C. Leva, N. Balfe, T. Kontigiannis, E. Plot, M. Demichela Total Safety Management: what are the main areas of concern in the integration of best available methods and tools?

Chem. Eng. Trans., 36 (2014), pp. 559-564

MIL-STD-882E, 2012 MIL-STD-882E, 2012. DoD Standard Practice for System Safety.

Monferini et al., 2013 A. Monferini, M. Konstandinidou, Z. Nivolianitou, S. Weber, T. Kontogiannis, P. Kafka, M.C. Leva, M. Demichela

A compound methodology to assess the impact of human and organizational factors impact on the risk level of hazardous industrial plants

Reliab. Eng. Syst. Saf., 119 (2013), pp. 280-289

Article PDF (2MB)

PAS 55, 2008 PAS 55:2008. Institute of Asset Management (retrieved 20

February 2015). 
Patterson and Neailey, 2002 F.D. Patterson, K. Neailey

\section{A risk register database system to aid the management of project}

risk

Int. J. Project Manage., 20 (2002), pp. 365-374

Article PDF (252KB)

Reason, 1997 J. Reason

Managing the Risks of Organisational Accidents

Ashgate, Aldershot (1997)

Whipple and Pitblado, 2010 T. Whipple, R. Pitblado

Applied risk-based process safety: a consolidated risk register and focus on risk communication

Process Saf. Prog., 29 (1) (2010), pp. 39-46

(c) 2017 Published by Elsevier Ltd.

About ScienceDirect Remote access Shopping cart

Contact and support Terms and conditions Privacy policy

Cookies are used by this site. For more information, visit the cookies

page.

Copyright $\odot 2017$ Elsevier B.V. or its licensors or contributors.

ScienceDirect ${ }^{\circledR}$ is a registered trademark of Elsevier B.V. 